\title{
Desain Multipurpose Landing Craft Tank (LCT) Menggunakan Metode Optimisasi Global dan Lokal
}

\author{
Varisha Vada Zumar dan Hasanudin \\ Departemen Teknik Perkapalan, Fakultas Teknologi Kelautan, Institut Teknologi Sepuluh Nopember \\ (ITS) \\ e-mail: hasanudin@na.its.ac.id
}

\begin{abstract}
Abstrak-Multipurpose LCT (Landing Craft Tank) dikenal sangat efisien untuk pengangkutan alat berat, pekerjaan pertambangan dan proyek konstruksi. Keberadaaan multipurpose LCT diharapkan mampu membantu perkembangan daerah terpencil di Indonesia, salah satunya kabupaten Kepulauan Mentawai. Metode optimasi sangat tepat untuk menyelesaikan persoalan desain kapal yang kompleks. Pemodelan optimisasi yang akan digunakan adalah gabungan dari optimisasi global dan lokal. Metode optimisasi global dan lokal ini dinilai mampu menentukan nilai ukuran utama kapal yang optimum. Pada global optimization, nilai yang didapatkan bersifat umum atau global sehingga hasil yang didapatkan kurang mampu mencapai nilai optima. Oleh karena itu digunakan optimasi lokal untuk mengatasi kelemahan tersebut. Optimasi global menggunakan metode Artificial Neural Network (ANN) dan optimisasi lokal menggunakan metode Generalized Reduced Gradient (GRG). Optimasi dilakukan dengan pembuatan program add-ins pada Microsoft Excel menggunakan Visual Basic For Application (VBA). Fungsi objektif yaitu meminimumkan biaya pembangunan kapal. Dari hasil optimisasi global didapatkan 7 kombinasi ukuran utama dari 10000 kombinasi ukuran utama yang memenuhi batasan optimasi. Perbandingan antara fungsi objektif terminimum optimasi global dengan optimasi global dan lokal yang memenuhi seluruh batasan optimisasi adalah $4.19 \%$. Perbandingan antara nilai fungsi objektif maksimum dan minimum pada optimasi global adalah 7\%, sedangkan perbandingan antara nilai fungsi objektif maksimum dan minimum pada gabungan optimasi global dan lokal adalah $10 \%$. Hasil optimisasi gabungan metode global dan lokal menghasilkan fungsi objektif yang lebih optimum.
\end{abstract}

Kata Kunci-Landing Craft Tank, Global Optimization, Local Optimization, Visual basic for application.

\section{PENDAHULUAN}

$\mathbf{M}$ ULTIPURPOSE LCT tidak memerlukan pelabuhan yang besar untuk mendaratkan barang yang diangkutnya dan bisa melakukan bongkar muat hampir di mana saja termasuk pulau-pulau terpencil di Indonesia. Oleh karena itu, keberadaaan multipurpose LCT diharapkan mampu membantu perkembangan daerah terpencil di Indonesia, salah satunya kabupaten Kepulauan Mentawai.

Spiral Design Process mempunyai kelemahan yaitu prosesnya selalu diulang-ulang secara manual beberapa putaran untuk memenuhi semua constraints sehingga memerlukan waktu yang lama atau hasilnya tidak optimal. Untuk mengatasi hal tersebut digunakanlah metode optimisasi sehingga diharapkan dapat mengurangi pengulangan perancanaan seperti desain spiral [1]. Pada umumnya, ada 2 metode yang digunakan untuk menyelesaikan persoalan optimisasi yaitu optimisasi global dan optimisasi lokal. Kedua metode ini memiliki kelemahan masing-masing. Kekurangan dari kedua metode ini dapat diatasi, salah satunya dengan penggabungan optimisasi global dan lokal [2][3]. Penggabungan optimisasi global dan lokal bertujuan untuk mendapatkan nilai optimum dari fungsi objektif yang sudah ditentukan.

Pada penelitian ini penyelesaian optimisasi global menggunakan sistem ANN dengan bantuan VBA yang sudah disediakan oleh Microsoft Excel. Sedangkan optimisasi lokal menggunakan tools solver. Pengaplikasian dua tahap optimisasi yang berbeda secara bersamaan tentu akan terlihat rumit. Oleh karena itu, dilakukan pembuatan add-ins pada Microsoft excel yang menggabungkan optimisasi global dan lokal dengan menggunakan VBA, sehingga diharapkan pengaplikasian optimisasi global dan lokal pada desain kapal dapat dilakukan dengan mudah dan cepat. Fungsi objektif (objective function) yang merupakan tujuan utama dalam proses optimisasi yaitu meminimalkan biaya pembangunan kapal, constrains yang digunakan adalah karakteristik teknis dan keselamatan kapal dan variabel optimisasinya adalah ukuran utama kapal.

\section{TINJAUAN PUSTAKA}

\section{A. Multipurpose Landing Craft Tank}

Landing Craft Tank adalah sebuah kapal pendarat serang untuk mendaratkan tank di tepi pantai. Kapal ini mulai muncul pada saat Perang Dunia II dan digunakan oleh Angkatan Laut Inggris dan Amerika Serikat [4]. Kapal jenis Landing Craft memiliki dek yang luas dan rata sehingga cocok untuk mengangkut kendaraan maupun bahan logistik ke daerahdaerah pertambangan; terutama yang terletak di pulau atau daerah terpencil [5]. Penggunaan kapal LCT sangat cocok dengan keadaan wilayah di Kepulauan Mentawai yang fasilitas pelabuhannya sangat minim [6].

\section{B. Kepulauan Mentawai}

Kabupaten Kepulauan Mentawai adalah salah satu kabupaten yang terletak di provinsi Sumatera Barat, Indonesia. Pemerintah pusat melalui Kementerian Perencanaan Pembangunan Nasional memasukkan Kepulauan Mentawai ke dalam 80 kabupaten tertinggal prioritas penanganan pada 2018 [7]. Percepatan pembangunan di Kabupaten Kepulauan Mentawai mengalami hambatan karena dipengaruhi letak 
geografis dan bentangan alamnya rawan bencana serta keterbatasan infrastruktur Fokus utama untuk mengeluarkan Mentawai dari daftar daerah tertinggal adalah pembangunan infrastruktur yang diharapkan mampu mengoneksikan daerahdaerah yang terisolir [8]. Fasilitas kapal yang beroperasi di sekitar kepulauan Mentawai tidak menjangkau masyarakat kepulauan Mentawai yang tinggal di pulau-pulau kecil pinggiran. Kapal-kapal baru yang ada cenderung beroperasi di daerah-daerah sekitar kota pusat yaitu Tuapeijat, Pulau Sipora Utara [9]. Mayoritas kapal yang beroperasi merupakan kapal penumpang sehingga muatan untuk barang terbatas.

\section{Optimasi Dalam Proses Desain}

Proses desain merupakan proses yang dilakukan secara berulang-ulang hingga menghasilkan suatu desain yang sesuai dengan apa yang diinginkan. Dalam proses desain pembangunan kapal baru terdapat beberapa tahap desain, yaitu antara lain [10]:
1) Concept Design
2) Preliminary Design
3) Contract Design
4) Detail Design

Metode optimasi sangat tepat untuk menyelesaikan persoalan desain desain kapal yang kompleks. Optimisasi ialah suatu proses untuk mencapai atau mendapatkan suatu hasil ideal yang optimum. Untuk mendapatkan nilai yang optimum dilakukan perubahan pada komponen variabel yang dibatasi oleh batasan-batasan dan objective function sebagai penentu tingkat optimal [11]. Optimisasi menggunakan satu objektif dapat diformulasikan dengan Persamaan 1.

$X=\left\{X 1_{2}, X 2_{2}, X 3_{2}{ }_{2}, X n\right)$

Dimana nilai $\mathrm{X}$ merupakan vector desain atau variabel pemilihan, dengan memaksimalkan fungsi objektif $f(x)$ yang berdasarkan batasan pada Persamaan 2 .

$$
\begin{aligned}
& g j(X) \leq 0, j=1,2 \ldots \ldots \ldots \ldots q) \\
& \text { dan } \\
& h j(X) \leq 0, j=q+1, q+2 \ldots m p)
\end{aligned}
$$

\section{Optimisasi Global dan Lokal}

Pada umumnya, ada 2 metode yang digunakan untuk menyelesaikan persoalan optimisasi yaitu optimisasi global dan lokal. Optimisasi global mengacu pada menemukan nilai optimal dari fungsi yang diberikan di antara semua solusi yang mungkin, sedangkan optimisasi lokal menemukan nilai optimal pada kandidat solusi .Optimisasi global maupun lokal masing-masing mempunyai kelemahan. Jika optimisasi hanya dilakukan dengan metode lokal maka pemecahan masalah hanya terbatas pada optima lokal yang nilai yang didapatkan berpeluang cukup jauh dari optima global dan dapat beresiko nilai yang didapatkan terjebak pada wilayah yang terendah sehingga menghasilkan nilai yang kurang optimal. Hal ini juga berlaku sebaliknya, jika metode optimisasi hanya menggunakan optimisasi global, maka nilai yang didapatkan bersifat umum/global namun hasil yang didapatkan kurang mampu mencapai nilai yang tertinggi (nilai optima), optimisasi global membutuhkan kalkulasi yang panjang agar nilai optima yang didapatkan akurat.
Untuk mengatasi kelemahan kedua metode optimasi tersebut, maka dilakukan penggabungan antara metode optimisasi global dan optimisasi lokal. Pada optimisasi global menggunakan jaringan saraf tiruan (JST) atau ANN. Neural Network merupakan kategori ilmu Soft Computing. Neural Network sebenarnya mengadopsi dari kemampuan otak manusia yang mampu memberikan stimulasi/rangsangan, melakukan proses, dan memberikan output [11]. Sedangkan optimisasi lokal menggunakan metode GRG. GRG mentransformasi ketidaksamaan batasan kedalam persamaan batasan melalui slack variable [12].

\section{E. VBA pada Microsoft Excel}

VBA adalah sebuah turunan bahasa pemrograman Visual Basic yang dikembangkan oleh Microsoft dan dirilis pada tahun 1993, atau kombinasi yang terintegrasi antara lingkungan pemrograman (Visual Basic Editor) dengan bahasa pemrograman Visual Basic yang memudahkan user untuk mendesain dan membangun program dalam aplikasi utama Microsoft Office, yang ditujukan untuk aplikasi-aplikasi tertentu [13].

\section{METODOLOGI PENELITIAN}

\section{A. Analisis Tinjauan Wilayah}

Tinjauan wilayah pada penelitian ini adalah Kabupaten Kepulauan Mentawai. Dalam analisis tinjauan wilayah dibutuhkan data-data berupa supply, demand dan proyek pemerintah di daerah tersebut.

\section{B. Pemodelan Optimasi}

Pembuatan pemodelan optimasi yang meliputi: variable, parameter, constanta, calculation process, constrains dan objective function. Variabel optimasi adalah menetukan ukuran utama kapal dengan fungsi objektifnya adaah meminimumkan biaya pembangunan kapal. Parameter dan constraints dari optimisasi didapatkan dari owner requirements yang telah dianalisis sebelumnya, regulasi dan peraturan statutory.

\section{Pembuatan Program}

Program atau aplikasi dibuat dengan menggunakan VBA yang tersedia di Microsoft Excel. Pembuatan program ini terdiri atas dua tahap utama, yaitu penyusunan userform dan melakukan coding program. Cara kerja program hampir serupa dengan add-ins solver yang tersedia di excel, namun pada program ini range dari variabel minimum dan maksimum dapat ditentukan sendiri. Sehingga pengguna dapat mendapatkan kombinasi variabel sesuai dengan kebutuhan. Diagram alir pembuatan program dapat dilihat pada Gambar 1 . 


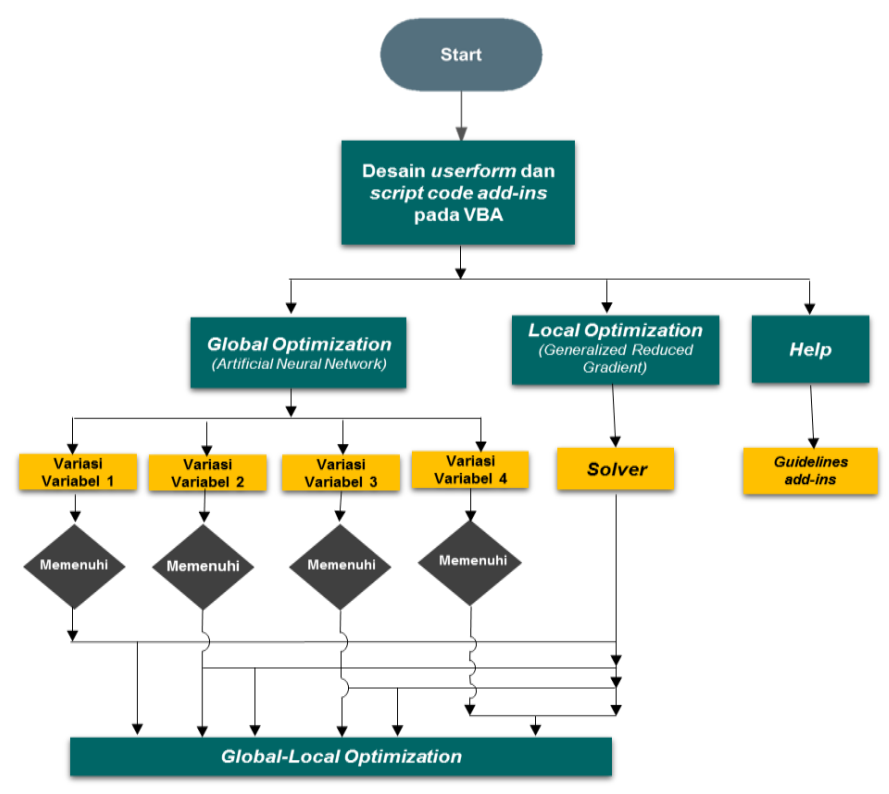

Gambar 1. Bagan Alir Pembuatan Program

\section{Analisis Teknis dan Optimasi}

Dari kombinasi variabel atau ukuran utama yang didapatkan dari program selanjutnya adalah melakukan penyaringan atau filter untuk mengetahui kombinasi ukuran utama yang memenuhi batasan. Jika hasilnya tidak memenuhi, maka kombinasi ukuran utama tersebut akan di eliminasi. Setelah hasil penyaringan kombinasi ukuran utama dilakukan, maka kombinasi ukuran utama yang baru dipilih berdasarkan nilai fungsi objektif yang terkecil.,

\section{E. Desain Model}

Pada tahap ini dilakukan perencanaan terhadap kapal ini sehingga didapatkan desain yang sesuai dengan karakteristik perairan di daerah pelayaran dan dapat diaplikasikan secara optimal. Perencanaan yang dilakukan adalah sebagai berikut:
a. Desian rencana garis
b. Desian rencana umum
c. Desain 3 dimensi

\section{ANALISIS OWNER REQUIREMENT}

\section{A. Muatan Alat Berat}

Estimasi jumlah dan tipe alat berat dilakukan berdasarkan proyek utama yang sedang dijalankan di kepulauan Mentawai yaitu pembangunan Trans Mentawai. Trans Mentawai merupakan proyek pembangunan jalan oleh pemerintah di seluruh kepulauan Mentawai yang dimulai sejak 2012 [14]. Dari hasil perhitungan dan estimasi, didapatkan jumlah alat berat yang dibutuhkan adalah 8-unit yaitu terdiri dari Excavator 4-unit, Bulldozer 2-unit dan Vibration Roller 2 unit. Estimasi berat payload untuk muatan alat berat yaitu 162 ton.

\section{B. Muatan Barang}

Total muatan barang yang akan diangkut oleh kapal dapat dihitung dengan menentukan besar supply dan demand terhadap kebutuhan pokok di Kabupaten Kepulauan Mentawai.
- Analisis Permintan Barang

Permintaan (demand) merupakan faktor yang sangat berpengaruh dalam menganalisis pergerakan barang yang terjadi. Dengan mengetahui jumlah permintaan yang ada di masing-masing kecamatan, maka dapat ditaksir jumlah calon muatan yang akan diangkut. Estimasi muatan permintaan barang didapatkan dari tingkat konsumsi beras dan produksi beras yang ada di Kabupaten Kepuluan Mentawai [15]. Hasil estimasi jumlah payload untuk muatan demand adalah 112 ton.

\section{- Analisis Supply Barang}

Komoditi unggulan Kabupaten Kepulauan Mentawai yaitu merupakan sektor pertanian, perkebunan, peternakan dan jasa. Estimasi muatan supply barang dilakukan dengan metode forecasting dengan menggunakan data sekunder dari BPS Kabupaten Kepulauan Mentawai tahun 2012-2016 [7]. Frekuensi pelayaran yang direncanakan yaitu untuk setiap 4 hari, sehingga jumlah truk dalam satu trip adalah 15 truk. Sehingga payload untuk muatan barang (supply) dapat diestimasi yaitu sebesar 153 ton.

Berat payload untuk multipurpose LCT diambil dari nilai yang terbesar dari hasil analisa payload yaitu 162 ton. Rute pelayaran yang diambil yaitu rute yang tercepat yang ditempuh kapal adalah Teluk Bayur sebagai Pelabuhan Asal -Sikakap - Sioban - Tuaipejat - Maileppet - Pokai -- Teluk Bayur dengan total jarak sebesar 348.95 nautical miles. Estimasi lama pelayaran yaitu 1 hari 4 jam 50 menit atau sekitar 29 jam. Rute Pelayaran dapat dilihat pada Gambar 2

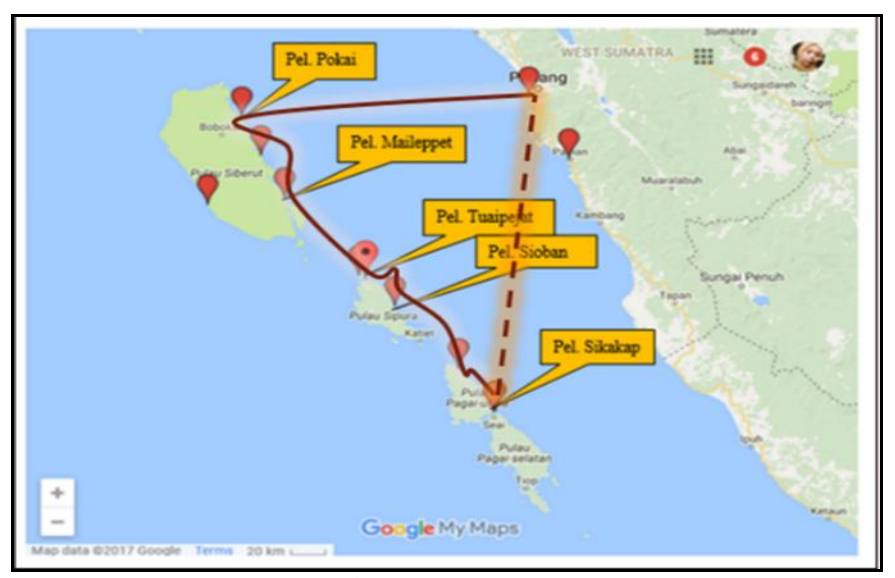

Gambar 2. Rute Pelayaran Optimum

\section{PEMBUATAN PROGRAM}

\section{A. Macro pada Visual Basic for Application}

Excel adalah salah satu produk keluarga Microsoft Office yang mana memiliki Macro untuk proses otomatisasi. Macro adalah sebuah script pada sebuah aplikasi untuk melakukan pekerjaan yang sama secara berulang-ulang [11][8]. Membuat program untuk aplikasi perhitungan sebenarnya sama dengan membuat suatu prosedur macro untuk otomasi langkahlangkah pekerjaan di dalam worksheets. Oleh karena itu, nilai objek menjadi strategis. Adapun tahapan-tahapan operasi dalam VBA adalah:

- Membaca input data dari worksheets. 
- Mengeksekusi input data dalam VBA.

- Mencetak hasil ke worksheets.

\section{B. Pemodelan Interface (Userform)}

Permodelan userform menggunakan bantuan toolbox yang telah disediakan oleh VBA. Dengan bantuan toolbox, pengguna dapat mendesain model dan penempatan layout userform sesuai dengan keinginan. Pengguna dapat memodelkan command button, text box maupun option button pada program yang direncanakan. Pada program ini dibagi menjadi 3 form yaitu: Global Optimization, Local Optimization dan GOLOC Optimization.

\section{Penulisan Code Program}

Setelah membuat form yang direncanakan adalah penulisan code dimana sebuah perangkat lunak akan menjalankan perintah sesuai dengan code yang ditulis. Penulisan code ini berfungsi agar tiap objek yang terdapat pada userform dapat berfungsi dan dapat dijalankan. Pemrograman code menggunakan bahasa visual basic. Penulisan code dibagi sesuai dengan objek masing-masing.

\section{Running Program}

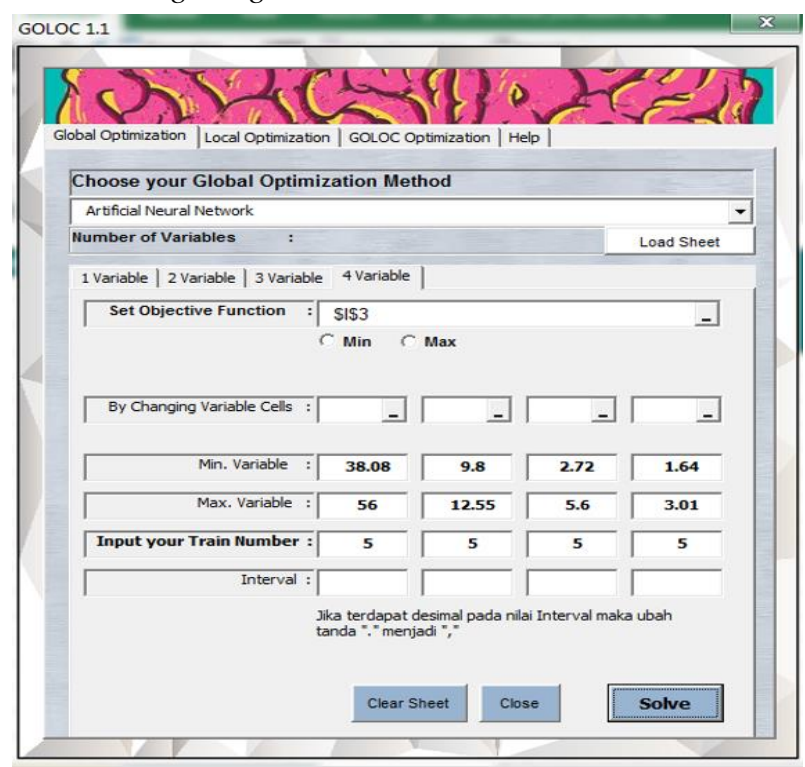

Gambar 3. Hasil akhir userform program add ins

Setelah userform dan penulisan code selesai, maka langkah selanjutnya adalah melakukan running program. Frekuensi waktu running program bervariasi sesuai dengan jumlah variasi variabel dan banyaknya nilai train yang ingin digunakan. Lama waktu running juga bergantung pada rumus untuk fungsi objektif, semakin rumit rumus yang digunakan maka waktu running pun semakin lama. Hasil desain userform program dapat dilihat pada Gambar 3

\section{ANALISIS TEKNIS DAN OPTIMASI}

\section{A. Analisis Teknis}

Analisis teknis dan pemodelan optimisasi kapal multipurpose LCT menggunakan microsoft excel dengan total jumlah worksheet adalah 13. Penentuan batasan rasio ukuran utama kapal LCT menggunakan 20 kapal pembanding dan berdasarkan ukuran muatan alat berat dan truk yang direncanakan.

\section{- Batasan Optimisasi (constraints)}

Batasan (constraints) merupakan fungsi yang berhubungan dengan variabel desain. Batasan tersebut didefinisikan sebagai range dari solusi yang dapat diambil dari berbagai solusi terbaik yang harus ditemukan. Constraints adalah batasan yang ditentukan oleh desainer dan regulation, batasan ditentukan berkaitan dengan proporsional geometri lambung, performance dan regulation. Pemodelan optimisasi pada penelitian ini menggunakan batasan yaitu batasan rasio ukuran utama, batasan margin displasemen [16], batasan stabilitas IMO [17], batasan Freeboard berdasarkan ICLL [201], batasan luas deck area dan batasan Gross Tonnage berdasarkan ICTM tahun 1969 [18].

\section{- Perhitungan Teknis Kapal}

Perhitungan teknis kapal berupa perhitungan Hambatan dan Daya mesin menggunakan metode Holtrop dan Mennen [19], perhitungan berat dan titik berat menggunakan metode Watson pada Practical Ship Design [20] dan perhitungan batasan sesuai dengan batasan optimisasi yang telah ditentukan.

- Perhitungan Biaya Pembangunan Kapal

Biaya investasi dapat diartikan sebagai biaya pembangunan kapal yang terdiri dari biaya material untuk struktur bangun kapal, biaya peralatan, biaya permesinan, dan biaya pekerja, modal cost, asuransi, perawatan, pajak pemerintah, dll. Biaya investasi kapal dibagi menjadi 5 bagian yaitu [21]:

1. Biaya pembangunan material (structural weight cost)

2. Biaya permesinan (machinery cost)

3. Biaya peralatan dan perlengkapaan (hull outfitting cost)

4. Non-weight cost dan koreksi keadaan ekonomi dan kebijakan pemerintah.

\section{B. Analisis Optimasi}

\section{- Analisis Optimasi Global}

Pada optimisasi global, program add ins mampu melakukan optimisasi sampai dengan 4 variasi variabel. Pada variasi 4 variabel nilai train dibatasi yaitu 5 hingga 10 . Pada optimisasi multipurpose LCT digunakan nilai train maksimal untuk 4 variasi ukuran utama, sehingga dari hasil optimisasi dapat dihasilkan 10000 variasi ukuran utama. Dari 10000 variasi ukuran utama, terdapat 7 variasi ukuran utama yang memenuhi seluruh batasan optimasi. Variasi variabel ukuran utama pada train ke-1012 merupakan nilai variabel yang paling optimum dengan nilai fungsi objektif terminimum, yaitu Rp.19.597.862.902.62.

- Analisis Gabungan Optimasi Global dan Lokal

Nilai inisial untuk optimisasi lokal dengan Solver didapatkan dari dari 7 kombinasi variabel yang memenuhi batasan pada optimisasi global. Dari hasil optimisasi lokal, terdapat 5 nilai ukuran utama yang memenuhi batasan optimisasi. Nilai fungsi objektif terminimum adalah sebesar Rp. 18.022 200.135,91. 
Dari hasil kedua metode optimisasi, dapat disimpulkan jika hasil optimasi gabungan metode global dan lokal menghasilkan fungsi objektif yang lebih optimum dengan nilai yang lebih minimum. Perbandingan antara nilai minimum optimasi global dengan optimasi global dan lokal yang memenuhi seluruh batasan optimasi adalah 4.19\%. Dari hasil gabungan 2 metode optimisasi global dan lokal, didapatkan ukuran utama multipurpose LCT yang optimum. Hasil optimasi dapat dilihat pada Tabel 1.

Tabel 1.

Hasil Optimisasi Global + Lokal

\begin{tabular}{lcccc}
\hline \hline \multicolumn{1}{c}{ Variables } & Unit & Min. & Optimum & Max. \\
\hline Lpp: & $\mathrm{m}$ & 38.08 & 41.16 & 56.00 \\
Breadth: & $\mathrm{m}$ & 9.80 & 9.80 & 12.55 \\
Height: & $\mathrm{m}$ & 2.7 & 3.05 & 5.6 \\
Draught: & $\mathrm{m}$ & 1.5 & 1.72 & 3.4 \\
\hline \hline \multicolumn{1}{c}{ Constraints } & Unit & Min. & Optimum & Max. \\
\hline Margin (Disp. - Weight): & ton & $-0.5 \%$ & $0.37 \%$ & $0.5 \%$ \\
Deck Area: & $\mathrm{m} 2$ & 133.23 & 262.19 & 333.07 \\
Gross Tonage: & & 200.0 & 229.67 & 300.0 \\
Freeboard: & $\mathrm{cm}$ & 0.3 & 1.33 & 1.6 \\
Initial Gmo: & $\mathrm{m}$ & 0.23 & 3.62 & - \\
Area $0^{\circ}$ to 30 $0^{\circ}:$ & $\mathrm{m} . \operatorname{deg}$ & 0.30 & 0.48 & - \\
Area $0^{\circ}$ to $40^{\circ}:$ & $\mathrm{m} . \mathrm{deg}$ & 0.1 & 0.80 & - \\
Area $30^{\circ}$ to $40^{\circ}:$ & $\mathrm{m} . \mathrm{deg}$ & 0.1 & 0.32 & - \\
Rolling Period: & $\mathrm{Sec}$ & 5.00 & 6.71 & 12.00 \\
Maks. GZ at 30 or greater: & & 25.00 & 50.00 & - \\
Lpp/B: & $\mathrm{m}$ & 4.0 & 4.20 & 5.2 \\
Lpp/H: & $\mathrm{m}$ & 10.0 & 13.50 & 20.0 \\
B/T: & $\mathrm{m}$ & 3.70 & 5.70 & 6.00 \\
H/T: & $\mathrm{m}$ & 1.30 & 1.77 & 2.22 \\
\hline \hline
\end{tabular}

\section{Desain Rencana Garis}

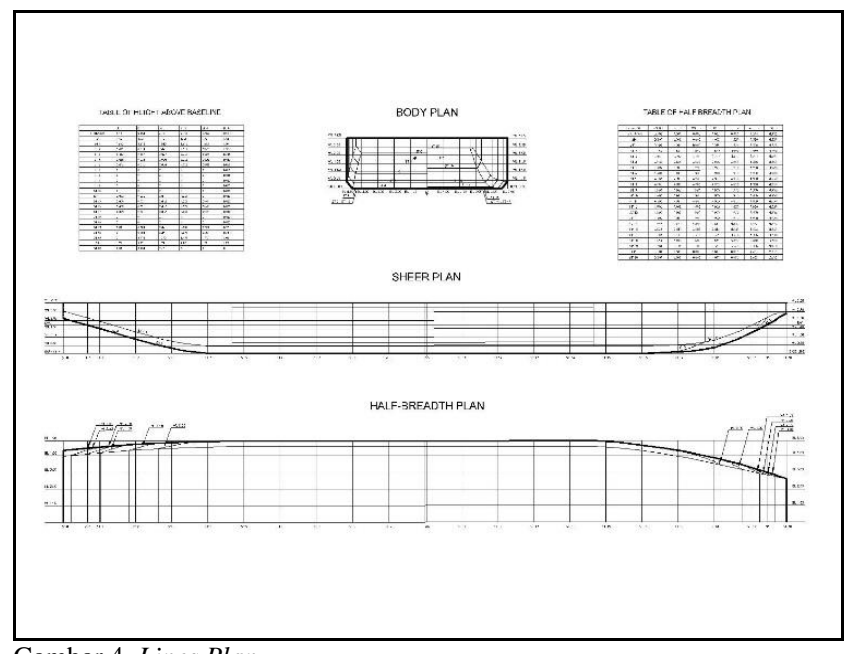

Gambar 4. Lines Plan

Proses pembuatan desain rencana garis dimulai setelah ukuran utama kapal diketahui. Adapun desain rencana garis multipurpose LCT ini dapat dilihat pada Gambar 4.

\section{Desain Rencana Umum}

Pembuatan General Arrangement untuk dilakukan untuk merencanakan ruangan yang dibutuhkan sesuai dengan fungsi dan perlengkapan kapal. Hasil Desain General Arrangement dapat dilihat pada Gambar 5.

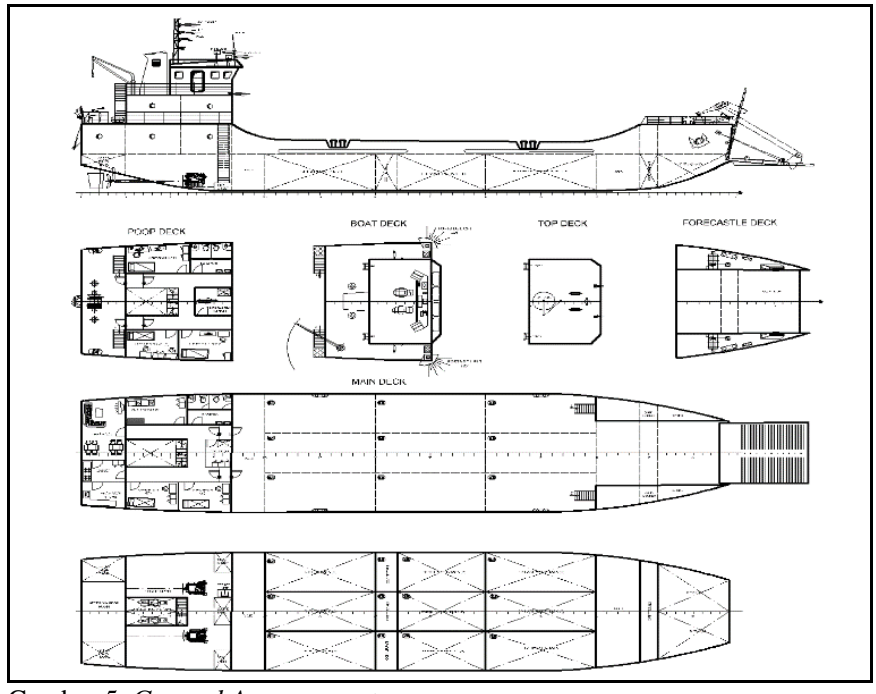

Gambar 5. General Arrangement

\section{E. Desain 3 Dimensi}

Pada tahap awal pemodelan 3D, pembuatan lambung kapal menggunakan bantuan software Maxsurf Modeler. Setelah itu, hasil pemodelan lambung kapal di Maxsurf Modeler diexport ke software Rhinoceros 5, untuk memudahkan pemodelan bangunan atas dan detail pada bagian main deck dan navigation deck. Desain 3 dimensi dapat dilihat pada Gambar 6.

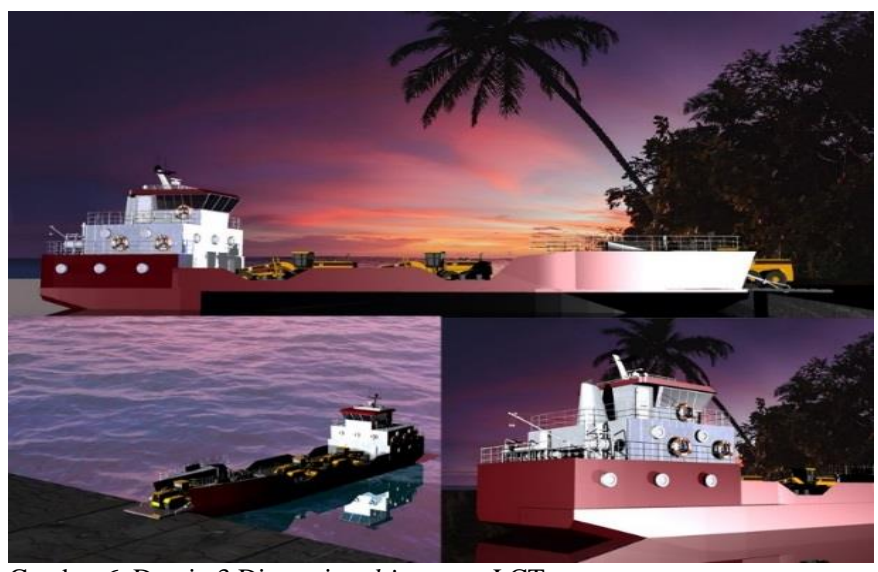

Gambar 6. Desain 3 Dimensi multipurpose LCT

\section{KESIMPULAN}

Berdasarkan uraian dari penelitian ini, dapat diambil kesimpulan sebagai berikut:

1) Analisis owner requirement untuk multipurpose LCT di kabupaten kepulauan Mentawai berupa payload, rute dan frekuensi pelayaran. Payload yang direncanakan yaitu muatan barang dan alat berat. Berat payload untuk multipurpose LCT diambil dari nilai yang terbesar dari hasil analisa payload yaitu 162 ton. Rute pelayaran yang diambil yaitu rute yang tercepat yang ditempuh kapal adalah Teluk Bayur (Pelabuhan Asal-Sikakap-SiobanTuaipejat-Maileppet-Pokai-Teluk Bayur (Pelabuhan Asal) dengan total jarak sebesar 348.95 nautical miles. Estimasi lama pelayaran yaitu 1 hari 4 jam 50 menit atau sekitar 29 jam. 
2) Program add-ins yang dibuat berfungsi untuk melakukan optimisasi global dan lokal di Microsoft Excel. Optimisasi global menggunakan metode artificial neural network (ANN) sedangkan optimisasi lokal menggunakan metode generalized reduced gradient (GRG) dengan bantuan Solver yang sudah tersambung dengan Microsoft Excel. Pada optimisasi global, program add ins mampu melakukan optimisasi sampai dengan 4 variasi variabel.

3) Pemodelan optimisasi kapal multipurpose LCT menggunakan microsoft excel dengan total jumlah worksheet adalah 13. Dari 10000 variasi ukuran utama, terdapat 7 variasi ukuran utama yang memenuhi seluruh batasan optimasi. Fungsi objektif atau biaya pembangunan kapal setelah dilakukan optimisasi lokal adalah Rp. 18.022 200.135,91. Perbandingan antara nilai minimum optimasi global dengan optimasi global dan lokal adalah $4.19 \%$.

4) Ukuran utama optimum yang memenuhi seluruh batasan dengan nilai fungsi objektif terminimum adalah sebagai berikut:

- $\mathrm{Lpp}=41.16 \mathrm{~m}$

- $\mathrm{B}=9.80 \mathrm{~m}$

- $\mathrm{H}=3.05 \mathrm{~m}$

- $\mathrm{T}=1.72 \mathrm{~m}$.

Dari ukuran utama optimum tersebut dibuat desain rencana garis (lines plan), rencana umum (general arrangement) dan pemodelan 3D kapal multipurpose LCT.

\section{UCAPAN TERIMA KASIH}

Ucapan terima kasih ditujukan kepada Hasanudin S.T., M.T. selaku dosen pembimbing penulis yang telah meluangkan waktu untuk memberikan masukan, bimbingan dan motivasi selama pengerjaan dan penyusunan dalam penelitian ini.

\section{DAFTAR PUSTAKA}

[1] O. Yeniay, "A comparative study on optimization methods for the constrained nonlinear programming problems," in Math Problem Engineering, 2005, pp. 165-173.

[2] V. Schneekluth, H and Bertram, Ship design for efficiency and economy-2nd edition. London: British Library Cataloguing in Publication Data, 1998.

[3] A. Hasanudin and Baidowi, "Ship Principal Dimension Optimization Using GOLOC Method," 2nd Int. Jt. Conf. Adv. Eng. Technol., 2017.

[4] R. N. UK, "Royal Marines," Landing Craft, 2016. [Online]. Available: https://www.royalnavy.mod.uk/ .

[5] Wikipedia, "Landing Craft Tank," 2017. [Online]. Available: https://id.wikipedia.org/wiki/LCT.

[6] Ratson, "Ratson Shipbuilding," 2017. [Online]. Available: http://www.ratson.com/Bintannow.

[7] BAPPEDA, Peraturan Daerah Rencana Pembangunan Jangka Menengah Daerah. Pemerintah Daerah Kabupaten Mentawai, 2016.

[8] BAPPENAS, "Pembangunan Infrastruktur Mentawai Mendesak," 2017. [Online]. Available: http://nasional.republika.co.id/.

[9] Pualliggoubat, "Menghitung kebutuhan jumlah titik lampu dalam ruangan," $2017 . \quad$ [Online]. Available: http://www.cvalfaelektro.wordpress.com/2012/12/11/menghitungkebutuhan-jumlah-titik-lampu-dalam-ruangan/.

[10] T. Ray, "A Global Optimization Model for Ship Design," Indian Institute of Technology, 1993.

[11] G. . Younis, Handling Complexity Aspects in Conceptual Ship Design. UK, 2011.

[12] Hasanudin, "Desain Kapal LCT TNI-AL Menggunakan Metode Optimisasi," ITS, 2015.

[13] S. Rizky, Optimalisasi Excel. Sidoarjo: Thousand Star Press, 2007.

[14] D. D. Notoprasetio, "Optimasi Biaya Penggunaan Alat Berat Pada Proyek Pembangunan Underpass Mayjen Sungkono Surabaya," Institut Teknologi Sepuluh Nopember, 2017.

[15] Pualliggoubat, Swasembada Beras di Mentawai Belum Tercapai. 2017.

[16] ICTM, International Convention on Tonnage Measurement of Ship. 1969.

[17] IMO, International Conference on Tonase Measurement of Ship. London: IMO, 1983.

[18] IMO, International Convention of Load Lines 1966 and Protocol of 1988. London: IMO Publishing, 2002.

[19] H. and Mennen, "An Approximation Power Prediction Method," Int. Shipbuild., vol. 25, 1982.

[20] R. Taggart, Ship Design and Construction Chapter 5. SNAME, 1980.

[21] D. Watson, "Practical Ship Design," Elsevier, vol. 1, 1998. 